\title{
Disease-free life expectancy has not improved in Spain
}

\author{
Pilar Zueras, Institute for Social and Economic Research, University of Essex, and Centre d'Estudis Demogràfics and \\ Elisenda Rentería, Centre d'Estudis Demogràfics
}

The COVID-19 pandemic has put a stop to the continuous progression in life expectancy at birth, in which Spain was one of the world leaders. Although this downward effect is a result of the present conjuncture and it is hoped that recovery will be swift in the coming years, this situation has led us to consider the evolution prior to the pandemic. It is true that the increase in number of years of life has been progressive and steady but, in recent years, these gains have not implied improved health among the older population. Disability-free life expectancy at the age of 65 has been very stable over time, but the figures are less encouraging when the presence of diseases and chronic conditions are taken into account. In this issue of Perspectives Demogràfiques, we investigate whether there have been gains or losses in years of disease-free life for men and women at the age of 65 in Spain and by autonomous community (AC) in the years 2006, 2012, and 2017. The results indicate that increased life expectancy will also mean that people will live more time with diagnosed diseases unless the present trend is reversed. The most common ailments and conditions include hypertension, chronic back pain, diabetes, and heart disease. The differences between men and women tend to converge in years of life in good health, mainly as a result of a lengthening of time lived in poor health among men.

\section{LIFE EXPECTANCY AND INCREASED TIME LIVED WITH DISEASES}

Life expectancy in Spain is currently among the highest in the world, with 80.9 years for men and 86.2 for women in 2019. This positive growth has been observed uninterruptedly since the 1970s. However, one must also ask whether these gains in terms of lifespan also include good health, especially among the older population. According to data from the National Statistics Institute (INE), life expectancy in good health at birth has increased in the last 15 years, yet the number of years lived in good health after the age of 65 have remained quite stable despite increased life expectancy (INE, 2020). The most common measure for defining good health is based on the absence of functional limitations or disabilities. Yet, it is important to know what happens with other health indicators, establishing how much of our lives we will spend with chronic diseases or adverse conditions of health. This perspective is relevant because chronic diseases are a major determinant

FIGURE 1. Evolution of life expectancy at the age of 65 and years lived with and without disease
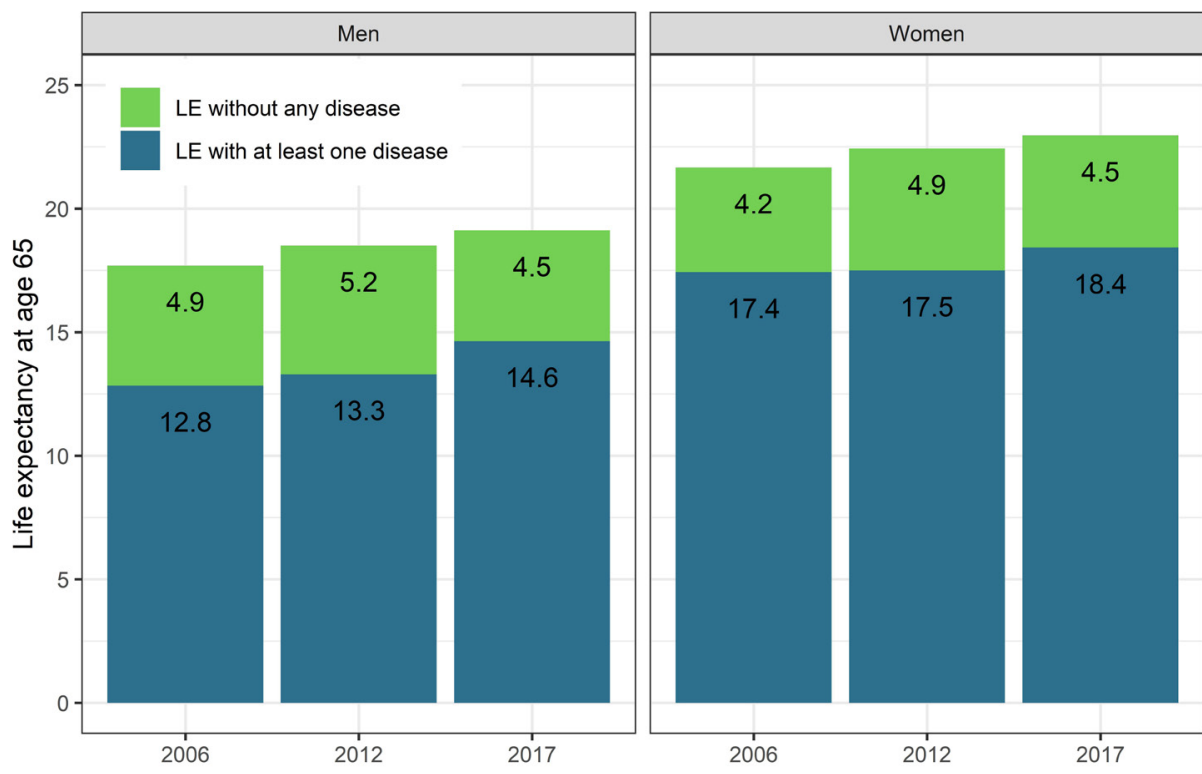

Source: INE and ENSE 2006, 2012, 2017 of quality of life. They are related with many health problems, they increase the risk of dying younger, and they define the level of use and the kinds of interventions carried out by health services.

Increased life expectancy results from health improvements that delay death. If death is deferred at the same pace as the age of onset of disease or health problems, what is called extension of morbidity occurs or, in other words, people live more years in bad health. However, if the age at which diseases appear is delayed, two things might happen. First, if this age increases more slowly than life expectancy, extension of morbidity would once again be the result. But if age at the onset of health problems is 
delayed faster than the increase in life expectancy, there would be a compression of morbidity, which would be more concentrated in the last years of life. Data from national health surveys combined with data of mortality by age enable us to investigate whether there has been compression or expansion of morbidity in Spain in recent years-that is to say whether the amount of time lived in bad health has increased or decreased. Hence, we can calculate the time of life expectancy with chronic illness or health conditions after the age of 65 for Spain and determine whether this is distributed differently among the ACs. Given the differences between the sexes in mortality and morbidity, we shall analyse the recent evolution separately for men and women. We use data from the national health surveys of 2006, 2012, and 2017 in which we investigate the presence of health problems including asthma, cancer, diabetes, stroke, hypertension, myocardial infarction, heart disease, chronic obstructive pulmonary disease (COPD), and chronic back pain, while bearing in mind that most of them are related with COVID-19 mortality. We use what is known as Sullivan's method which is based on applying the proportions of individuals with one of the selected health problems to a life table. The calculation, based on specific observations, by sex and five-year age groups, of the presence of disease and deaths makes it possible to obtain the time of life expectancy (after a certain age) lived with each of the conditions, with at least one of them, or without any.

Figure 1 shows the evolution of life expectancy at 65 years for men and women between 2006 and 2017 together with the evolution of life expectancy at this age with at least one of the specified health problems. Life expectancy shows lineal growth from 17.7 to 19.1 years for men, and from 21.7 to 23.0 years for women. At the same time, the number of disease-free years shows a more stable evolution with a slight rise between 2006 and 2012, after which it drops again between 2012 and 2017, although always remaining at about 5 years for men and a little less for women. Additionally, while the number of years lived with at least one health problem has risen at a slow rate between 2006 and 2012 it has shown a greater increase between 2012 and 2017, especially among men. As for differences by sex, women consistently show a higher life expectancy than men in all the years. However, when we observe the evolution of years lived in good health, we confirm that there is convergence between the two sexes where, in 2006, men lived more years without these health problems, but in 2017 the time lived in good health was comparable to that for women. In any case, since women have a greater life expectancy than men, the time lived with health problems is also longer for them throughout this period. Despite the years of life gained between 2006 and 2017-1.3 for men and 1.4 for womenmen have lost 0.4 disease-free years $(-26.7 \%$ of the rise in life expectancy) and women have gained 0.3 years (23.9\% of their increase). But the impact and evolution of the diseases has not been the same for men and women.

\section{GENDER DIFFERENCES IN THE TIME LIVED WITH EACH DISEASE}

This study covers nine health conditions that are especially relevant for different reasons. Cancer and cardiovascular and cerebrovascular diseases (stroke, myocardial infarction, and other heart diseases) were among the five main causes of death in Spain during the period analysed. Moreover, we have considered two health problems that are cardiovascular risk factors (hypertension and diabetes), as well as including back pain (chronic lumbar and cervical pain), which was the main factor associated with years lived with disability in Spain in 2016. Finally, we have also examined asthma and chronic obstructive pulmonary disease (COPD), the two most frequent respiratory diseases. By contrast, inclusion of high cholesterol has been ruled out because part of the observed increase is due to the change in diagnostic parameters in the period between the different health surveys. Neither has it been possible to include other diseases that cause functional impairment (like
FIGURE 2. Evolution of the proportion of life expectancy at the age of 65 lived with each disease, by sex

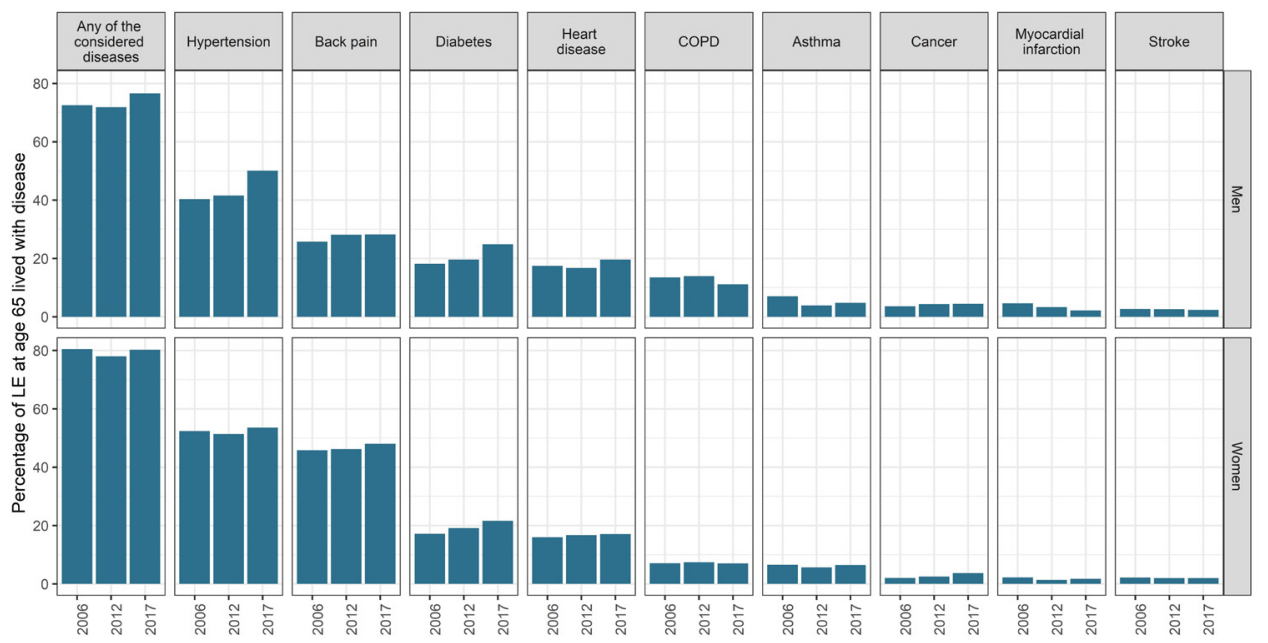

Source: INE and ENSE 2006, 2012, 2017 
osteoarthritis) because of an absence of comparability between the surveys. Some of the health conditions we have taken into account are not only the chief causes of mortality and the burden of illness and disability, but they are also risk factors associated with the severity of COVID-19 and the resulting hospitalisation. When we analyse each of the diseases and health conditions separately, we can see in Figure 2 which ones have the greatest impact on the time lived in poor health, and if there are differences due to sex. Suffering from hypertension is the most common health condition. In the age group of over 65, men lived 9.6 years with this in 2017 , and women 12.3 years, which represents $53.6 \%$ and $50.1 \%$ of time left to live for men and women respectively. Having chronic back pain was the next most prevalent condition, especially for women, and it accounts for $28.2 \%$ of life expectancy at the age of 65 for men and $48.0 \%$ for women in 2017.

With many of the diseases it is possible to observe a sustained increase in life expectancy lived with the ailment (hypertension only for men, heart disease only for women, and chronic back pain, diabetes, and cancer for men and women) but the increase has been especially significant because of hypertension and diabetes among men. The evolution has been different with other diseases (asthma for men and women, heart disease for men, and hypertension and myocardial infarction for women), for which the proportion of time lived with the disease has diminished or remained steady between 2006 and 2012 but has risen between 2012 and 2017. In the case of COPD, it increased in 2012 and decreased in 2017 for both men and women. Finally, some diseases have shown a decrease in the proportion of time lived with them between 2006 and 2017 (stroke for both men and women and, for men, myocardial infarction as well). In the case of these two latter health conditions, and also that of COPD, compression of morbidity is observed.

\section{EVOLUTION AND HETEROGENEITY IN THE ACS: CROSSING PATHS BETWEEN MEN AND WOMEN}

Both life expectancy and years lived with good or bad health present variability at the AC level. Figure 3 shows the distribution of the different indicators among the 17 ACs studied, separated by sex and year. Life expectancy is more consistent and there is less variation between regions, with a progressive increase everywhere. As for life expectancy with at least one disease, and disease-free life expectancy, heterogeneity is present in all years and is lower in 2012 for men and in 2006 for women but, in both cases, 2017 seems to be the year when the differences between the ACs have increased to the greatest extent. This rise in heterogeneity of life expectancy with at least one disease at the age of 65 is reflected in a difference of values among the ACs of 5.2 years for men and 5.4 years for women whereas, in 2006, the difference was only 4.0 years for men and 3.3 years for women. In many ACs, as a result of steady figures and a slight decrease in the amount of time lived without diseases, especially among men, there has been a rise in the number of years lived with one or more diseases between 2006 and 2017. In the case of years lived in good health, the convergent evolution between the sexes means that, by 2017 , the situation of women had become equal to or better than that of men in most of the ACs, reproducing the results at the national level.

FIGURE 3. Regional heterogeneity of changes in life expectancy at the age of 65

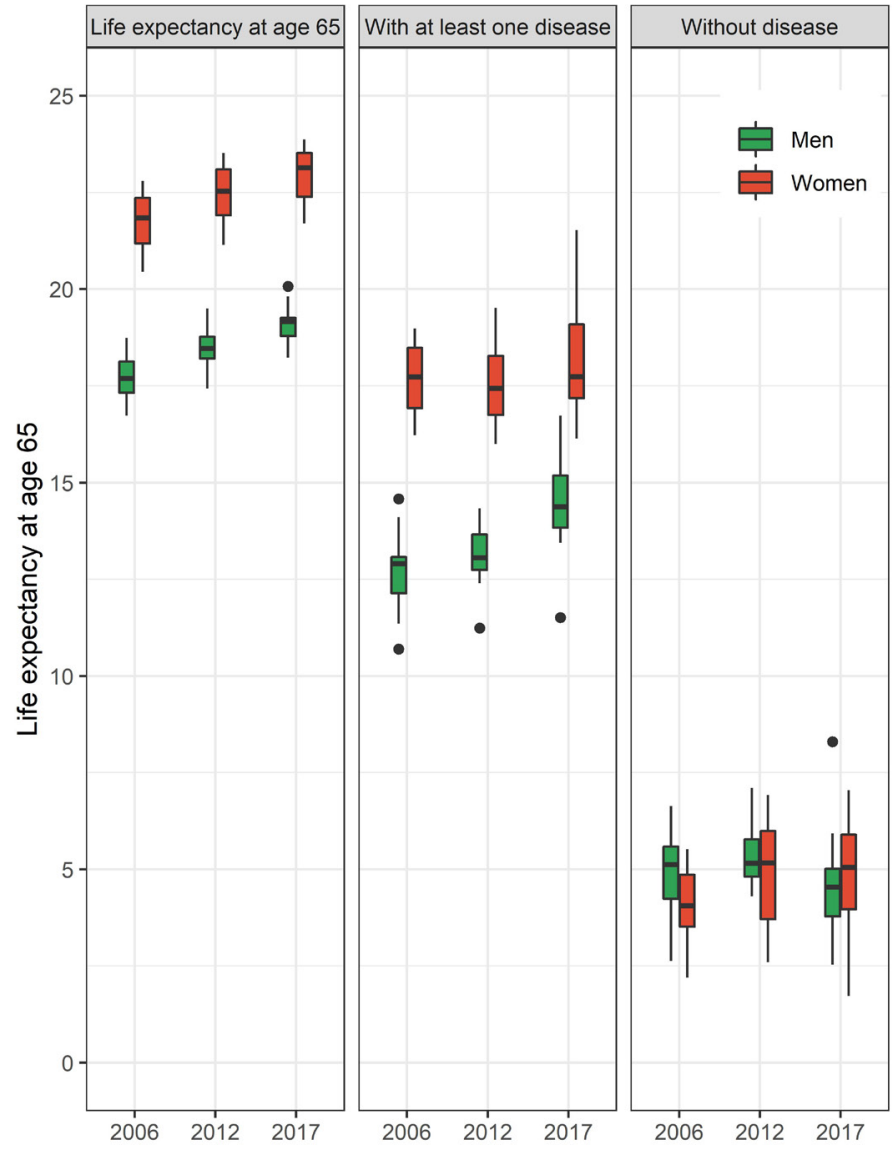

Source: INE and ENSE 2006, 2012, 2017

Note: All ACs included but the Autonomous Cities of Ceuta and Melilla. 


\section{MORBIDITY COMPRESSION: A PRIORITY GOAL}

Reversing the tendency where prolonged life expectancy at advanced ages is accompanied by stagnation in terms of years of healthy life should be a priority goal of the health system in the coming years. After the age of 65 , the presence of diseases and health problems has not diminished since 2006, which has led to a greater number of years lived in bad health, especially among men. Having hypertension, chronic back pain, diabetes, and heart diseases are the most common conditions for men and women. And, for the great majority of diseases and conditions considered, the time lived with them has remained unchanged or has increased. Moreover, this stagnation with regard to improvements in the number of years lived in good health has been more pronounced between 2012 and 2017, a period in which the differences between the ACs also widened. A very diverse range of factors explains this trend. To begin with, improvements in the health system have focused more on dealing with acute cases closer to death, which leads to a better survival rate but also to a greater number of individuals living with diseases or health problems. Furthermore, diet has been steadily worsening in the last few years throughout the whole population and this, together with a decline in physical activity, has caused an increase in the body mass index (Basterra-Gortari et al., 2017), which inevitably has negative consequences in the prevalence of diseases and health problems like hypertension, diabetes, heart diseases, stroke, and cancer. However, these trends have not occurred in a similar way over the territory, which suggests that policies aimed at improving the health of the older people could be implemented. Furthermore, there are significant differences between men and women, most notably the fact that, in recent years, men have shown more pronounced stagnation with regard to their health than women have. This evolution could be behind the apparent paradox of the greater incidence and severity of COVID-19 in the male population. Women are more exposed to infection due to their prevalence in care work, their larger presence in the health sector, and the feminisation of old age. Nevertheless, the greater imbalance in the worsening of diseases that has come with the gains of longer life among men found in this study would shed some light on the fact that COVID-19 mortality is greater among men than among women.

\section{Bibliography}

Basterra-Gortari, F. J. Bes-Rastrollo, M.; Ruiz-Canela, M.; Gea, A.; Martinez-González, M. Á. (2017) "Prevalence of obesity and diabetes in Spanish adults 1987-2012". Medicina Clínica: 148 (6): 250-256 (DOI: 10.1016/j.medcli.2016.11.022).

INE (2020) Mujeres y Hombres en España, 2020. Salud. 4.2. Esperanza de vida en buena salud [Internet]. 2020 [citado 15 de diciembre de 2020]. Link

Soriano,, J. B.; Rojas-Rueda, D.; Alonso, J.; Antó, J. M.; Cardona, P.-J.; Fernández, E. et al. (2018) "La carga de enfermedad en España: resultados del Estudio de la Carga Global de las Enfermedades 2016”. Medicina Clínica: 151 (5): 171-190 (DOI: 10.1016/j.medcli.2018.05.011)

Zueras P.; Rentería, E. (2020) "Trends in disease-free life expectancy at age 65 in Spain: Diverging patterns by sex, region and disease". PLOS ONE, 15 (11): e0240923 (DOI: 10.1371/journal. pone.0240923).

\section{Citation}

Zueras, P. and Rentería, E. (2021) "Disease-free life expectancy has not improved in Spain". Perspectives Demogràfiques, 22: 1-4 (ISSN: 26964228). DOI: 10.46710/ced.pd.eng.22.

ISSN

ISSN 2696-4228

DOI

https://doi.org/10.46710/ced. pd.eng.22

Editors:

Andreu Domingo and Albert Esteve (Centre d'Estudis Demogràfics)

Please address correspondence to:

Pilar Zueras

pzueras@ced.uab.es

Elisenda Rentería

erenteria@ced.uab.es

\section{Acknowledgements:}

We acknolwedge funding from the Economic and Social Research Council (UK) Research Centre on Micro-Social Change at the University of Essex ("grant number" ES/So12486/1), the "Plan Estatal de Investigación Científica y Técnica y de Innovación 2013-2016. Programa Estatal de Promoción del Talento y su Empleabilidad, Subprograma Estatal de Formación y en el Subprograma Estatal de Incorporación: Ayudas para Contratos Ramón y Cajal 2017" (grant number RYC-2017-22586) and the project 'HEALIN' (ERC-2019- CoG-GA No 864616).

\section{Credits}

Graphics: Anna Turu

Layout: Xavier Ruiz Vilchez

URL

https://ced.uab.cat/en/difussion/ butlleti-perspectives-demografiques/
Contact

Centre d'Estudis Demogràfics. Carrer de Ca n’Altayó, Edifici E2 Universitat Autònoma de Barcelona o8193 Bellaterra / Barcelona Spain

Telephone: +34935813060 Email:demog@ced.uab.cat Web page: www.ced.uab.cat

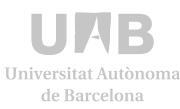

